\title{
Creation Of An Autonomous Electric Car Charging Mechanism Which Does Not Require Plug-In To Charge Its Batteries
}

\author{
Christos P Beretas* \\ Information Technology and Cyber Security, Innovative Knowledge Institute, Paris, FranceA
}

*Corresponding author: Christos P Beretas, MSc, Ph.D, Information Technology and Cyber Security, Innovative Knowledge Institute, Paris, France

\begin{abstract}
The future of the car is in electrification, electrification is still in its infancy, in relation to the experience that exists with internal combustion engines, but also have a major environmental disadvantage as well as for the production of electricity, in various countries carried out with the use of oil with the combustion of lignite, this has as a consequence the burden on the environment. My research proposal is based on the philosophy that with e-mobility begins a new ecological era, on the one hand cannot create ecological cars and on the other hand to burden the environment for the increasing use of energy that will be required when it grows the percentage of use of electric cars. My proposal is to create a servo mechanism, ie the common winder, which will be placed in the charging place of the cars, that is, the usual refueling place of today's cars that use solid fuels. Tuning the winder will activate a mechanism which each time that slowly unwind the winder will generate electricity, the power of the energy produced will be able to move the vehicle autonomously and simultaneously charge its batteries.
\end{abstract}

\section{Methodology}

The use of a servo mechanism, ie a slow tuning tuner, will be able to start a power generating mechanism, ie a generator, this tuner will be in the charging place of the cars, ie the refueling place of today's cars that use fossil fuels. By rolling the winder and until it is completely unwinding it will be able to:

a. Generates the electricity required to move the vehicle.

b. To charge the batteries of the electric car at the same time.

This means that the driver of an electric car has available energy from two sources, both from the generator using the winder and from the car batteries, the car batteries can be charged in other ways as for example during the use of brakes. Also, if the driver of an electric car runs out of power, may simply tune the tuner and start the power generation process.

\section{Benefits}

a. Environmentally friendly energy production.

b. No charge of the electric car is required in the power supply.

c. Unlimited autonomy in use.

d. The batteries of the electric car can be charged at night simply by tuning the servo mechanism late at night. e. When the battery life is reduced, the driver tunes the vehicle and generates power to start the car and charge the batteries immediately.

\section{Presentation}

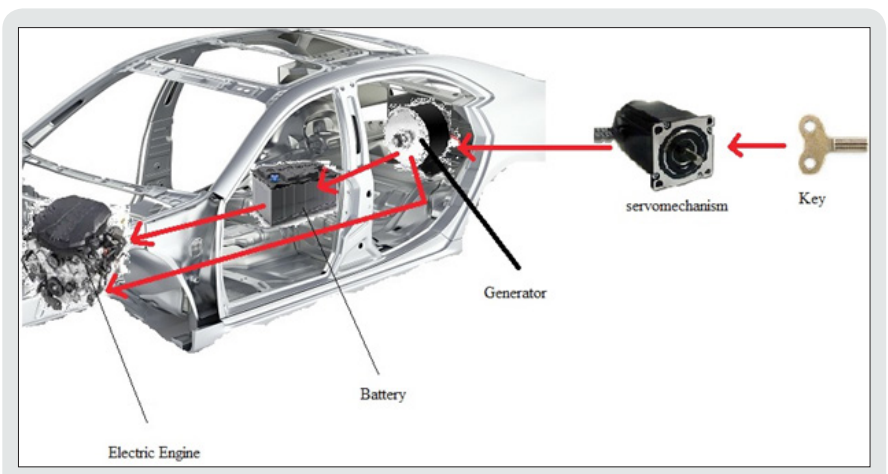

Figure 1: Presentation.

\section{Conclusion}

This is a smart way to generate energy for moving electric cars and charging their batteries in parallel to achieve greater autonomy for their driving. It is an ecological solution that does not burden the environment as the energy created is mechanical and autonomous. 
The automakers may benefit from this project and have a ROI from the following:
a. From the batteries.
b. From the parts of the servomechanism.

c. From the power generator parts.

d. From other parts that need to be replaced.

\section{(c) (1) \\ This work is licensed under Creative Commons Attribution 4.0 License}

To Submit Your Article Click Here:

Submit Article
DOI: 10.32474/MAMS.2021.04.000191

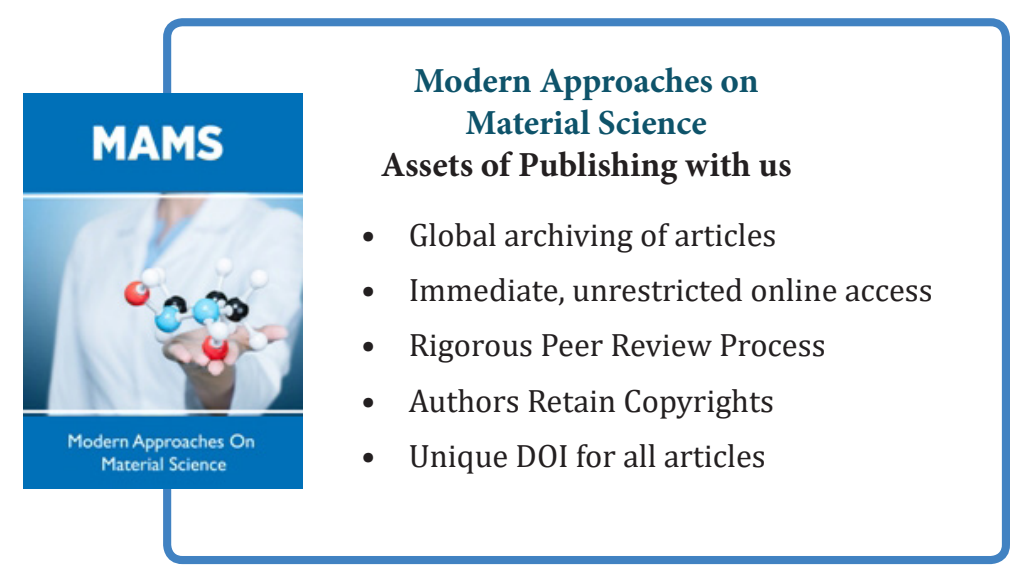

